\title{
NOTAS DE LEITURA DA OBRA DE LUCIE TANGUY: A PESQUISA COMO ATIVIDADE SOCIAL E A RELAÇÃO ENTRE CIÊNCIA E POLÍTICA
}

\author{
Liliana Rolfsen Petrilli Segnini*
}

\begin{abstract}
RESUMO: Destacar duas dimensões analíticas a partir da leitura do último livro de Lucie Tanguy, que nos estimula a refletir sobre nossa sociedade e a sociologia brasileira - da educação e do trabalho -, mesmo considerando as dessemelhanças e diferenças de nossas trajetórias históricas. Refiro-me à pesquisa como atividade social e às relações entre ciência e política. Recuperar as formas de poluição e domesticação da sociologia (Florestan Fernandes), especialmente do trabalho e da educação, é uma das tarefas que nos é imposta por meio da leitura do livro de Lucie Tanguy. Para nós, a história da sociologia permanece, ainda muito frequentemente, como uma história dos autores, temas e teorias gerais. Lucie Tanguy foi além, buscou compreender as fontes nos arquivos que informavam as relações de poder - econômicas e sociais - na constituição de uma disciplina e as trajetórias acadêmicas de seus pesquisadores. Ela "levantou o véu" da produção do conhecimento, procurando sua importância na relação entre educação (formação) e trabalho (produtividade).

Palavras-chave: Modernização. Produção do conhecimento. Sociologia. Atividade social. Relações entre ciência e política.
\end{abstract}

ReAding notes of the Lucie TANguy work:

\section{THE RESEARCH AS SOCIAL ACTIVITY AND THE RELATIONSHIP} BETWEEN SCIENCE AND POLITICS

\begin{abstract}
Highlight two aspects which the reading of the last book by Lucie Tanguy encourages us to reflect on ourselves, our society and sociology in Brazil - the education and work - even considering the differences and dissimilarities of our historical trajectories. I refer to research as social activity and the relationship between science and politics. Recover the form of pollution and domestication of sociology (Florestan Fernandes), especially in work and education, is one of the tasks imposed on us by reading the book of Lucie Tanguy. For us, the history of sociology still remains too often,
\end{abstract}

Doutora em Ciências Sociais e professora titular da Faculdade de Educação e do Instituto de Filosofia e Ciências Humanas, da Universidade Estadual de Campinas (Unicamp). E-mail: lilianaseg@uol.com.br 
as a story of the authors, themes and general theories. Lucie Tanguy went further, sought sources in the file that tells the relations of power-economic and social - in the constitution of a discipline and the academic trajectories of its researchers. She "lifted the veil" of knowledge production, looking for their importance in the relationship between education (training) and work (productivity).

Key words: Modernization. Production of knowledge. Sociology. Social activity. Relations between science and politics.

\section{Notes de lecture sur l'oeuvre de Lucie Tanguy:}

\section{LA RECHERCHE COMME ACTIVITE SOCIALE ET LA RELATION ENTRE SCIENCE ET POLITIQUE}

RÉSUMÉ: Mettre en exergue deux dimensions tirées de la lecture du dernier livre de Lucie Tanguy est une incitation à réfléchir sur nous-mêmes, notre société et la sociologie brésilienne - de l'éducation et du travail - même en considérant les dissemblances et les différences de nos trajectoires historiques. Je me réfère à la recherche comme activité sociale et aux relations entre science et politique. Récupérer les formes de pollution et de domestication de la sociologie (Florestan Fernandes), particulièrement du travail et de l'éducation, est une des tâches qui nous est imposée par la lecture du livre de Lucie Tanguy. Pour nous, l'histoire de la sociologie reste, encore très fréquemment, comme une histoire des auteurs, thèmes et théories générales. Lucie Tanguy est allée au-delà, elle a cherché à comprendre les sources dans les documents qui informaient des relations de pouvoir - économiques et sociales - dans la constitution d'une discipline et les trajectoires universitaires des chercheurs. Elle a "levé le voile" de la production des connaîssances, cherchant son importance dans la relation entre éducation (formation) et travail (productivité).

Mots-clés: Modernisation. Production de la connaîssance. Sociologie. Activité sociale. Relations entre science et politique.

\section{Introdução}

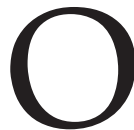

objetivo deste texto é analisar questões selecionadas na obra mais recente da socióloga francesa Lucie Tanguy, intitulada La sociologie du travail en France. Enquête sur le travail des sociologues, 1950-1990 (Tanguy, 2011).

Não farei uma comparação entre os resultados de pesquisa na construção de um campo disciplinar na França e a história da sociologia do trabalho e suas interfaces com a educação no Brasil, pelo menos não no sentido atribuído pelo historiador Marc Bloch.

O autor afirma que comparar sociedades contemporâneas implica "(...) escolher em um ou vários meios sociais diferentes, dois ou vários fenômenos que parecem, à primeira vista, apresentar certas analogias entre si, descrever as curvas da sua evolução, encontrar as semelhanças e as diferenças e, na medida do possível, 
explicar umas e outras" (Bloch, 1998, p. 121). Para o historiador, são necessárias, portanto, duas condições para que haja, historicamente falando, uma comparação: "uma certa semelhança entre os fatos observados - o que é evidente - e uma certa dessemelhança entre os meios onde tiveram lugar" (idem, ibid.) Assim, o autor se refere ao objeto e aos processos selecionados - nomeados fatos observados - e às sociedades nos quais se inscrevem - dessemelhanças entre os meios.

É por considerar relevante esta orientação teórica e metodológica que não me sinto autorizada a fazer uma comparação França/Brasil, tomando o livro de Lucie Tanguy como referência para a realização de uma "leitura brasileira" dos achados de sua pesquisa. Por que não buscarei as semelhanças entre fatos observados, no caso o processo de modernização no Brasil, e as dessemelhanças, considerando a constituição de campos do conhecimento e de pesquisa - a sociologia do trabalho e da educação - no Brasil, em relação à França?

Respondo: por absoluta falta de pesquisa em nosso país, a partir de fontes semelhantes (ou de mesmo porte), tal como Lucie Tanguy realizou, ou seja, nos arquivos do Ministério do Trabalho e do Centre National des Recherches Scientifiques (CNRS), tecendo a história intelectual e social destas instituições francesas, de uma comunidade implicada na construção de uma disciplina, considerando a relevância do período histórico compreendido entre o pós-guerra (1950) e as mudanças observadas até os anos de 1990. Assim, novamente encontro na análise de Bloch justificativa (neste caso, sociológica) que aponta para as fontes e documentação como impedimentos à comparação:

\begin{abstract}
Com efeito, vejamos o que muitas vezes se passa. Numa dada sociedade, manifestou-se um fenômeno com tanta amplitude e, sobretudo, teve tantas consequências e tão visíveis - nomeadamente no domínio político, sendo os prolongamentos desta natureza habitualmente mais fáceis de captar nas nossas fontes - que, a menos que sofra de cegueira, o historiador não pode deixar de captá-lo em cheio no olhar. Tomemos agora a sociedade vizinha. Talvez se tenham dado aí factos análogos e com uma força e extensão quase paralelas; mas, seja por causa do estado da nossa documentação, seja devido a uma constituição social e política diferente, a sua acção é aí menos imediatamente perceptível. (Bloch, op. cit., p. 123-124)
\end{abstract}

Juarez Brandão Lopes já havia nos alertado sobre essa lacuna na história da sociologia do trabalho no Brasil. Ele, memória viva desse processo, um dos principais representantes da geração dos fundadores desse campo do conhecimento (como bem analisa Leite Lopes neste mesmo Dossiê). Participando do último seminário CNRS/ Fapesp referente ao projeto "Qual é o sentido social da modernização do trabalho?", realizado na Unicamp em 2008, após ouvir a comunicação de Lucie Tanguy (naquele momento a pesquisa estava em curso), ele ressaltou que se fazia urgente a elaboração de indagações sociológicas, tendo por objeto o papel de nossas instituições políticas e 
de pesquisas e considerando seus próprios arquivos. Assim, propunha a compreensão dos fatos observados, além das entrevistas e depoimentos dos partícipes do processo, na construção da Sociologia como campo científico no Brasil. Destacou a sociologia do trabalho, mas também se referia à sua articulação com a educação, considerando, assim como Tanguy, a relevância do período pós-guerra até o presente.

\section{Pesquisas no Brasil: exemplos selecionados}

No entanto, temos sim pesquisas realizadas, e em realização, que contribuem para a construção do conhecimento sociológico do trabalho no país; porém, por meio de outros caminhos metodológicos, dentre os quais destaco quatro grupos de pesquisas já realizadas e cito alguns autores, sem nenhuma preocupação em esgotar as referências, mas trazê-las tão somente como exemplos.

Em primeiro lugar, saliento as pesquisas que privilegiaram entrevistas e depoimentos com os fundadores da sociologia do trabalho no Brasil, dentre os quais volto a destacar o depoimento analítico do sociólogo Juarez Brandão Lopes (disponível em: http://gepedisc.blogspot.com/). Neste depoimento ele se refere aos primeiros contatos, no final dos anos de 1950, estabelecidos entre George Friedmann e Alain Touraine com sociólogos da Universidade de São Paulo para a criação do Centro de Estudos de Sociologia Industrial e do Trabalho (Cesit), vinculado à Cadeira I de Sociologia, coordenada por Florestan Fernandes. O artigo de José Sérgio Leite Lopes, neste Dossiê, já mencionado, significa relevante contribuição para o estado da arte sobre o tema no país nessa perspectiva metodológica.

Ressalto, em segundo lugar, as pesquisas que recuperaram temas constitutivos da história da Sociologia do Trabalho, tal como o artigo elaborado por Nadya Guimarães e Márcia Leite intitulado "A Sociologia do Trabalho industrial no Brasil: desafios e interpretações", publicado no Boletim Informativo e Bibliográfico de Ciências Sociais (Guimarães \& Leite, 1994). Saliento também publicações selecionadas, resultados de pesquisas de vários sociólogos críticos da presente geração, cujas obras indico na bibliografia. Dentre muitos que participam desse trabalho científico, destaco Helena Hirata (2002), Ricardo Antunes (2011), Cibele Saliba Risek (2011), Jacob Lima (2011), Angela Araújo (Leite \& Araújo, 2009), Iram Jácome Rodrigues (2011), José Ricardo Ramalho (Rodrigues \& Ramalho, 2007), Graça Druck (2001), Roberto Veras de Oliveira (Moreira \& Oliveira, 2009) e tantos outros que escrevem a história contemporânea do trabalho no Brasil por meio de pesquisas teóricas e de campo, entre os quais estão os autores dos artigos deste Dossiê.

Saliento também, em terceiro lugar, pesquisas realizadas por meio do levantamento das publicações em bibliotecas. Por exemplo: o trabalho de Gláucia Villas 
Bôas - A vocação das Ciências Sociais no Brasil - um estudo da sua produção em livros do Acervo da Biblioteca Nacional (2007). A autora privilegia o período 1945 a 1966 e pesquisa o acervo dos livros da Biblioteca Nacional do Rio de Janeiro com o objetivo de analisar a produção das Ciências Sociais. A análise dos temas da sociologia reconhece que a formulação do seu objeto "só foi possível com a ascensão da burguesia moderna" (Villas Bôas, 2007, p. 110). Portanto, é no contexto da sociedade urbana e industrial, no capitalismo, nas mudanças na estrutura social que surgem os principais temas sociológicos.

Todos eles indagam, em alguma medida, a relevância do trabalho neste contexto de transformações: a relação entre meio rural e urbano, migrantes e imigrantes, industrialização e desenvolvimento, religião, educação. No total, são 121 obras analisadas que informam o sentido das mudanças sociais no Brasil (idem, ibid.)

As pesquisas elaboradas por meio da seleção de temas observados nos projetos financiados pelas agências de fomento - CNPq, Capes, Fapesp - e pelas associações nacionais como Anpocs ou ANPEd são aqui também salientadas em quarto lugar. Entre elas, o trabalho analítico e compilador do sociólogo Sérgio Miceli, que elaborou a história social das Ciências Sociais no país, enfatizando o campo sociológico. Seu trabalho contribui para a compreensão das sociologias do trabalho e da educação, contextualizando-as num campo científico mais amplo (Miceli, 1989 e 2001).

Reitero: os exemplos apresentados constituem referências selecionadas, uma síntese aleatória da produção no campo da Sociologia, que não é exaustiva, longe disso! No entanto, é possível afirmar que a história da Sociologia permanece para nós, brasileiros, ainda muito frequentemente, como uma história dos autores, temas e teorias gerais.

Lucie Tanguy foi além, buscou suas fontes nos arquivos que informavam as relações de poder - econômicas, políticas e sociais - constitutivas de um campo de conhecimento, de uma disciplina e as trajetórias acadêmicas de seus pesquisadores. Ela "levantou o véu" da produção do conhecimento, procurando sua importância na relação entre trabalho (produtividade) e educação (formação). Os documentos que orientaram as pesquisas nos períodos analisados, bem como a apropriação política e econômica de seus resultados, constituíram suas fontes.

Para tanto, Tanguy explorou três arquivos até então nunca pesquisados: o do Institut des Sciences Sociales deu Travail (ISST), no período 1950 a 1960; os dossiês do Centre National de Recherche Scientifique (CNRS), nos anos de 1960 a 1970; bem como os documentos referentes ao Programme Interdisciplinaire de Technologie Travail, Emploie et Mode de Vie (Pirttem) e também ao programa Technologie, Travail et Emploi (TET), implementados pelo Estado francês após a eleição de François Mitterrand, primeiro presidente socialista, nos anos de 1980 a 1990 (Tanguy, 2011). 
Sobre o que pretendo refletir neste texto? Qual é sua contribuição?

Considerando o que já foi afirmado - não irei comparar os condicionantes institucionais de nossas histórias sociais da sociologia do trabalho e sua articulação com a sociologia da educação -, destacarei duas dimensões da leitura do último livro de Lucie Tanguy que nos estimulam a refletir sobre nós mesmos, nossa sociedade e a sociologia brasileira - quer seja do trabalho e ou da educação -, mesmo considerando as diferenças dos processos que informam nossas trajetórias históricas: a) a pesquisa como atividade social e b) relações entre ciência e política.

\section{A pesquisa como atividade social}

Tanguy afirma que a pesquisa como atividade social demanda a construção de uma abordagem que engloba, a uma só vez, diferentes e complementares aspectos. Ela aponta para oito dimensões, sem hierarquizá-las, as quais comentarei brevemente com o olhar de uma pesquisadora brasileira, tentando trazer alguns exemplos relacionados ao contexto nacional, passíveis de serem observados em uma agenda de pesquisa. Aglutinarei os referidos temas em decorrência da complementaridade analítica entre os mesmos.

\section{- Os quadros sociais e políticos nos quais ela nasce}

A "modernização da França", do período pós-guerra até os anos de 1990, informa o contexto no qual a autora inscreve suas pesquisas, indagando a relevância e o significado científico, político e econômico da sociologia do trabalho naquele país. Salienta os usos da noção de "modernização" em todos os momentos nos quais a vontade política introduzia elementos de ruptura com a situação anterior. Por exemplo: nos anos de 1950, sob forte influência do Plano Marshall; nos anos de 1980, quando a recupera, mas de forma diferente, com a chegada dos socialistas ao governo; e hoje, com a inserção no contexto do processo de globalização.

O termo "modernização" é compreendido pela autora de forma distinta da modernidade tal como compreendida no Renascimento. No entanto, ela reconhece que ainda empresta dele algumas ideias, tais como a noção de progresso e da dinâmica construtiva, da aceleração do tempo, do homem mestre de sua história, da humanidade sujeito dela mesma. Assim, dotado de uma conotação positiva, este termo é ideologicamente evocado para designar um conjunto de mudanças que deverão ocorrer e para engendrar a adesão necessária à sua realização (Tanguy, 2011).

No Brasil, a noção de modernização é também fortemente marcada pela ideologia. No entanto, temos dessemelhanças a considerar em relação à França. Fazer 
sociologia do trabalho ou da educação significa observar as especificidades nacionais na constituição das relações de trabalho e do campo educacional, considerando, em nossas análises, aspectos constitutivos do processo de urbanização e industrialização no período republicano: destaco a herança colonial e da escravatura, dimensões que teimosamente se expressam nas relações sociais até o presente. É relevante considerar também os longos períodos de ditadura, durante o século XX. A industrialização no Brasil e a expansão do capital monopolista foram fortemente marcadas pelas ditaduras de Getúlio Vargas (1930/1945) e pelo período militar (1964/1985). Em um século, 40 anos de ditadura a impulsionar, autoritariamente, o nomeado processo de modernização no país, no qual o trabalho e a educação se configuraram.

\section{- Os indivíduos e as instâncias que as impulsionam}

\section{- Os lugares onde as pesquisas se realizam}

\section{- As posições e trajetórias das primeiras gerações de pesquisadores nesse campo}

O Institut des Sciences Sociales du Travail (ISST) foi criado pelo Ministério do Trabalho, em 1951, com o objetivo de implementar pesquisas e ensino em Ciências Sociais, tendo por objeto as novas formas de gestão do trabalho. A ação é definida por uma política regida pela produtividade, com a assessoria econômica dos Estados Unidos expressa em missões de estudos informadas em seus respectivos relatórios. Essa missão de conhecimentos a serviço de um programa político - analisa Tanguy - procurava alterar as relações de trabalho nas empresas, constituir disciplinas para ensiná-las nas universidades, formar executivos para as empresas e também para os sindicatos. Havia, no período, um anseio no sentido de aproximar o mundo universitário do mundo do trabalho. Compreender as questões do trabalho era o objetivo, destinado a um público de profissionais que ocupavam diversos estatutos hierárquicos nas empresas ou em seu entorno e gerido por uma direção colegiada, composta por um número equivalente de representantes do Ministério do Trabalho e de universitários. Os professores foram, ao mesmo tempo, administradores do Ministério e das universidades.

A criação da revista Sociologie du Travail é tributária desta fase e seus fundadores passaram longos períodos em formação nos Estados Unidos. A primeira geração de sociólogos do trabalho, entre eles Georges Friedmann, Pierre Naville e Alain Touraine, é destacada pela pela autora.

No Brasil, a dimensão analítica que indaga pelas instituições e indivíduos que impulsionaram os primórdios da sociologia do trabalho já está parcialmente realizada, se consideradas as pesquisas anteriormente citadas. No entanto, há muito por 
fazer ainda, sobretudo se considerados os arquivos que informam o impulso alcançado pelas instituições universitárias, centros de pesquisa e os recursos governamentais para a manutenção das mesmas (Miceli, 2001).

A relevância política do eixo Rio de Janeiro-São Paulo na constituição do campo de pesquisa em sociologia (mesmo reconhecendo a contribuição de Minas Gerais, Bahia, Pernambuco e Rio Grande do Sul) expressa o poder econômico e político desses estados, traduzido em apoio às pesquisas realizadas nas universidades públicas e centros de investigação, financiadas por agências de fomento vinculadas ao Estado brasileiro e estrangeiras.

A forte influência da sociologia francesa e norte-americana para as primeiras gerações de sociólogos brasileiros já é objeto de pesquisas e seminários no país, há vários anos. Um exemplo sintetiza a questão pela sua relevância na criação de um campo de pesquisa - relações raciais -, mas com implicações para as sociologias do trabalho e da educação: refiro-me à pesquisa Unesco, coordenada por Florestan Fernandes e Roger Bastide, com o apoio da Revista Anhembi (Bastide \& Fernandes, 1955):

O programa de estudos, que se convencionou denominar Projeto Unesco, não apenas gerou um amplo e diversificado quadro das relações raciais no Brasil, mas também contribuiu para o surgimento de novas leituras acerca da sociedade brasileira em contexto de acelerado processo de modernização capitalista. De uma outra perspectiva, o Projeto Unesco veio a possibilitar a análise das trajetórias sociais e intelectuais dos pesquisadores envolvidos, das redes internacionais de cientistas, dos conteúdos teórico-metodológicos que informaram as pesquisas e do estado da arte de determinadas disciplinas, especialmente a Antropologia e a Sociologia. Ou seja, o ciclo de investigações chancelado pela instituição intergovernamental ofereceu uma oportunidade singular para o desenvolvimento das ciências sociais no Brasil dos anos de 1950. (Chor Maio, 1999, p. 141)

Neste projeto, vários estados e centros de pesquisa estiveram envolvidos. Em São Paulo, seus resultados foram elaborados por duas equipes de pesquisa, na mesma instituição (USP): o grupo de Florestan Fernandes privilegiou a análise do processo de integração do negro na estrutura social e econômica em transformação, sobretudo pela aceleração do processo de urbanização e industrialização, no qual a classe operária e o movimento sindical se fortaleciam. O grupo de Roger Bastide analisou o plano das mentalidades e as manifestações do preconceito na vida social, considerando o mesmo contexto.

O trabalho de Florestan Fernandes aponta para a associação entre as mudanças no perfil da população negra e as transformações da economia paulista. “Os movimentos característicos da 'população de cor' e as tendências à especialização profissional, que se processaram dentro dela, refletem de forma considerável as 
flutuações das 'fases' ou 'ciclos' de evolução da economia paulista" (Bastos, 2004). A autora destaca que, para Florestan, o negro incorpora-se à ordem competitiva, característica da sociedade de classes, somente após os anos de 1940, por meio da proletarização dos negros na vida econômica de São Paulo. Para o autor, esta é uma das expressões das formas como se operou a abolição, relegando o negro à condição de pária social, em uma circunstância em que o migrante (por exemplo) contava com vantagens objetivas (não adestrado no trabalho escravo) e subjetivas (era branco). As duas dimensões eram valorizadas nas relações de trabalho no processo de industrialização.

A pesquisa Unesco é, até o presente, fonte de discussões e análises acadêmicas que reiteram sua relevância para a compreensão do processo de modernização do país, desde aquele período, na perspectiva de classe social e raça.

\section{- Os temas e métodos adotados de forma privilegiada}

A análise dos relatórios das missões de pesquisa realizada por Tanguy possibilitou a identificação de uma política que induziu a hierarquização das temáticas e de dotações orçamentárias para concretizá-las. A pesquisa empírica, neste contexto, se impôs como método. Pouco a pouco, animados pela possibilidade de transformar a ordem social, os sociólogos acreditaram que poderiam colocar seus conhecimentos a serviço de uma causa considerada justa (Tanguy, 2011). Posteriormente, nos anos mais recentes, é registrada uma inflexão significativa, não em direção a uma sociologia crítica, mas à expertise. "Especialização, profissionalização e expertise" são os movimentos que sintetizam os caminhos da sociologia do trabalho no período analisado pela autora.

No Brasil, os campos de pesquisa da sociologia do trabalho privilegiaram o próprio desenvolvimento econômico: trabalho agrário, inicialmente; posteriormente, as relações de trabalho na indústria e o setor de serviços. O papel das migrações e das imigrações na constituição da força de trabalho no país; a relação entre urbanização e industrialização; movimentos sociais e sindicalismo constituem alguns subtemas de um tema central - o sentido das mudanças no processo de industrialização num país que foi, gradativamente, se modernizando e configurando, de forma desigual, as diferenças regionais, as relações sociais de classe, de gênero, raciais e geracionais.

A pesquisa empírica também se firmou no horizonte dos métodos: observar a realidade dos fatos e interpretá-los, mesmo quando dados quantitativos se mesclam a questionários (surveys), entrevistas, observação do campo de pesquisa. Em qualquer destas temáticas privilegiadas na perspectiva do trabalho, também é observado o processo de formação, incluindo escolarização, como se fosse um 
"bem universal", uma resposta aos anseios e interesses da sociedade, de cidadania. No entanto, trata-se de um poderoso instrumento de reforma política nos últimos 50 anos, como bem salienta Tanguy (1987), observado tanto na França como no Brasil.

\section{- A difusão destes trabalhos}

\section{- As relações internacionais tecidas}

\section{- As formas de trocas instauradas}

Nesta "agenda de pesquisa", a autora nos propõe indagar o significado da multiplicação de congressos, seminários, periódicos, bem como as políticas que orientam seus financiamentos, a obtenção de recursos para desenvolvê-las; a criação de revistas científicas e a lógica produtivista que frequentemente as orientam; a constituição das associações nacionais e internacionais mobilizadas para estruturar esses campos do conhecimento.

No Brasil, significa recuperar a história de associações criadas, não por acaso, a partir dos anos de 1970, indagando a relação estabelecida entre conhecimento e política, procurando as motivações que estão na base das relações sociais e econômicas que as criam e as fortalecem (ou não). Por exemplo: a Associação Nacional de Pós-Graduação e Pesquisa em Ciências Sociais (Anpocs), a Associação Brasileira dos Estudos do Trabalho (Abet), a Associação Nacional de Pós-Graduação e Pesquisa em Educação (ANPEd), e a Associação Latinoamericana de Sociologia do Trabalho (Alast).

Quanto às relações internacionais tecidas, importa indagar a gênese e o processo histórico dos acordos estabelecidos. Quais temas? Quais instituições implicadas? Quem são os pesquisadores envolvidos? Como são selecionados? Torno a trazer, somente como exemplos relevantes, o Acordo de Cooperação Científica Capes/Cofecub, se falarmos da relação Brasil/França, ou ainda os Acordos MEC/Usaid, nos anos de 1960, se a referência for os Estados Unidos. Outros países podem ser citados, tais como Portugal, Espanha e Alemanha.

É grande o desafio proposto nessas oito dimensões indicadas por Lucie Tanguy na tentativa de compreender a pesquisa como atividade social, bem distante de uma visão crítica pessimista, negativa, desconstrutiva, mas mobilizada pela crença de que o conhecimento do mundo possibilita sua transformação (Tanguy, 2011).

\section{A relação entre ciência e política}

Ao término da leitura do livro de Lucie Tanguy, uma imagem se impôs: tratase de Angelus Novus, uma aquarela de Paul Klee, de 1920. Hoje, ela está no Museu de 
Israel (Hessel, 2010). Pertenceu a Walter Benjamim, que ao anjo se referiu - sintetizando a preocupação expressa no livro de Tanguy - como o significado do progresso na relação entre ciência e política.

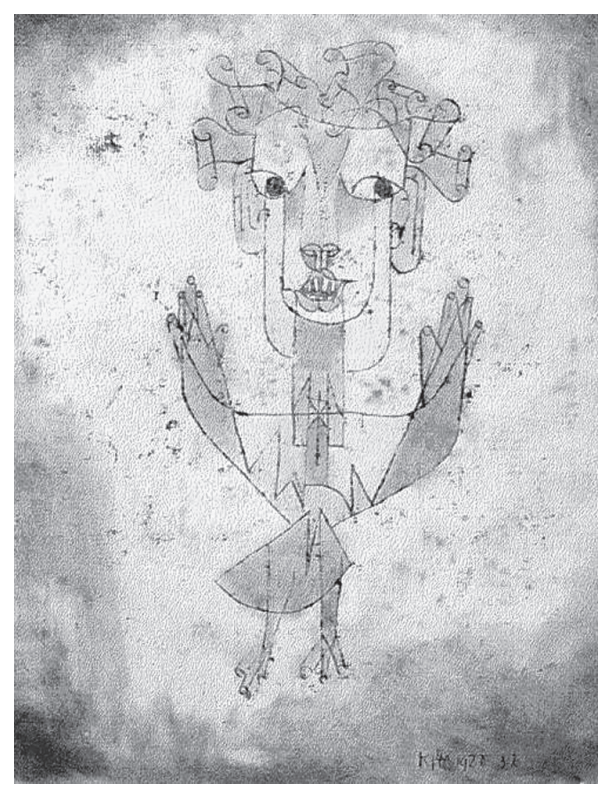

Onde aparece para nós uma cadeia de acontecimentos, ele vê uma única catástrofe que continua a amontoar destroços sobre destroços e os arroja a seus pés. O anjo gostaria de se deter, despertar os mortos e reunir o que foi despedaçado, mas está soprando uma tempestade no paraíso que o impele irresistivelmente para o futuro a que volta suas costas, enquanto à sua frente o monte de ruínas cresce em direção ao céu. O que chamamos de "Progresso" é justamente esta tempestade. (Benjamin apud Hessel, op. cit)

Tanguy indagou a história social do "progresso" na França, por meio de um campo de conhecimento e seu crucial papel na procura da modernização do país, por meio do crescimento da produtividade, desde a reconstrução no pós-guerra até os anos de 1990. A autora perguntou pelos rumos dessa tempestade (referida por Benjamin) e a relação estreita estabelecida com o processo de acumulação, por meio da constituição de um campo de pesquisa, de uma disciplina - a sociologia do trabalho e sua relação com a sociologia da educação -, de um coletivo de pesquisadores. A escolaridade e a formação profissional se encontram intimamente ligadas a esta dimensão, no contexto do processo de modernização marcado pelas exigências do crescimento da produtividade.

A ciência, nesta perspectiva, é "domesticada e poluída", tal como presente na reflexão de Florestan Fernandes, uma das maiores referências na construção da 
sociologia brasileira. Separados geograficamente e no tempo, ambos os autores, ao analisarem "sociologicamente a sociologia", no processo de modernização da sociedade capitalista, se referem aos problemas vividos por um campo científico - sociologia - quando submetido aos interesses políticos da ordem.

$1^{0} \mathrm{O}$ inegável crescimento quantitativo da sociologia, sob o capitalismo monopolista, não pode ser interpretado, pura e simplesmente, como um produto sadio dos "dinamismos da ciência" na civilização existente;

$2^{\underline{o}}$ Na relação entre ciência e sociedade, sob o capitalismo monopolista, aquela é completamente submetida aos "interesses da ordem", o que a converte em uma força cultural revolucionária, mas domesticada e poluída. (Fernandes, 1980, p. 53)

Recuperar as formas de poluição e domesticação da sociologia, especialmente do trabalho e da educação, é uma das tarefas que nos é imposta pela leitura do livro de Lucie Tanguy. Neste sentido, é preciso aprofundar o diálogo, os aspectos convergentes de sua análise com Florestan Fernandes, ao considerarmos a sociologia brasileira.

Para mim, como pesquisadora do processo de formação e de trabalho dos artistas no Brasil contemporâneo, a leitura do livro de Tanguy provoca a necessidade de responder a questões candentes, não menos amargas do que as referidas por Fernandes: por que, no presente momento histórico, se multiplicam as pesquisas no campo da Arte e do Espetáculo como espaço de formação e de trabalho? Por que o Estado investe na formação dos artistas, sobretudo no ensino superior, de forma mais incisiva do que as escolas privadas que se multiplicaram nas últimas décadas? Por que a gestão dos recursos públicos para a arte no país é, sobretudo, gerido pelas empresas, posto que seu financiamento é captado por meio da Lei do Mecenato (ou suas congêneres no âmbito dos estados e municípios), que possibilita a dedução de $100 \%$ do imposto de renda dos valores investidos em arte? Assim, reconhecendo que, no presente, compete, sobretudo, aos departamentos de marketing das grandes corporações a definição do que é arte e do que não é arte que merece ser financiada por meio de recursos públicos, indago: qual é o legado artístico que está em construção para as gerações futuras? Quais relações estabelecem com o capital e com o Estado? Provavelmente, o caminho para ir além da aparência e buscar sua essência pode estar nas tentativas de "despoluir" a sociologia do trabalho e a formação em arte, consultando os arquivos das instituições que formulam políticas públicas e de gestão neste campo.

Estas perguntas nascem dos desafios que o trabalho de Lucie Tanguy nos leva a considerar na relação sociológica entre a produção do conhecimento e o sentido do processo de modernização no presente. 


\title{
Considerações finais
}

Terminar um texto não significa concluí-lo e, ainda menos, apontar para soluções dos problemas colocados (Tanguy, op. cit.). Concordo com a autora.

No entanto, considerando o objetivo deste artigo - analisar duas questões selecionadas na obra recente de Lucie Tanguy - e os argumentos que subsidiaram a decisão de não comparar a constituição da sociologia do trabalho e sua interface com a educação - ausência de pesquisas em arquivos -, finalizo-o tecendo considerações metodológicas.

Para tanto, retomo Bloch, quando o historiador chama a atenção do leitor para o que não pode ser atribuído ao método comparativo:

\begin{abstract}
Mas cuidemos de não alimentar um mal-entendido de que o método comparado não sofre. Muitas vezes pensa-se, ou afecta-se pensar, que o método não tem outro objectivo que a caça às semelhanças; gosta-se de o acusar de se contentar com analogias forçadas, até mesmo, por vezes, de as inventar, postulando arbitrariamente não sei que paralelismo necessário entre as diversas evoluções. Inútil ir ver se estes reparos terão parecido por vezes justificados; é bem certo que o método, assim praticado, não passaria de uma maldosa caricatura. Pelo contrário, concebido com correcção, traz um interesse especialmente marcado à percepção das diferenças, sejam elas originais ou resultem de caminhos divergentes, tomados de um mesmo ponto de partida. (Bloch, 1998 , p. 131-132)
\end{abstract}

Exatamente neste sentido é possível observar que o mesmo ponto de partida - período pós-guerra, dos anos de 1950 aos anos de 1990 -, quando considerados dois países que viveram processos históricos diferentes, no contexto da expansão do processo de modernização capitalista e fortalecimento do capital monopolista, evoca semelhanças dentre as quais destaco a procura pela produtividade crescente que se entrelaça com a formação e a escolarização.

Para tanto, o livro de Lucie Tanguy cumpre seu desejado papel de "passeur", informando novas gerações sobre o que foi, sobre o que é a constituição de um campo sociológico de pesquisa.

\section{Nota}

1. 13/08/2008 - Sociologia do trabalho na França e no Brasil: história e perspectivas de um campo científico. Expositora francesa: Lucie Tanguy - "História da Sociologia do trabalho na França no pós-guerra"; Expositores brasileiros convidados: Antonio Dimas (FFLCH-USP); Juarez Brandão Lopes (IFCH-Unicamp); Letícia Bicalho Canêdo (FE-Unicamp); Márcia de Paula Leite (FEUnicamp); Nadya Araújo Guimarães (FFLCH-USP). Coordenação: Liliana Segnini (FE/IFCHUnicamp). 


\section{Referências}

ANTUNES, R. O continente do labor. São Paulo: Boitempo, 2011.

BASTIDE, R.; FERNANDES, F. (Org.). Relações raciais entre negros e brancos em São Paulo. São Paulo: Unesco; Anhembi, 1955.

BASTOS, É.R. Unesco/Anhembi: um debate sobre a situação do negro no Brasil; colóquio internacional Projeto Unesco no Brasil: uma volta crítica ao campo 50 anos depois. Salvador: Universidade Federal da Bahia, 2004. Disponível em: <http://www. ceao.ufba.br/unesco/welcome.htm>. Acesso em: 10 mar. 2012.

BLOCH, M. História e historiadores. Lisboa: Teorema, 1998.

CABANES, R. et al. (Org.). Saídas de emergência: ganhar/perder a vida na periferia de São Paulo. São Paulo: Boitempo, 2011.

CHOR MAIO, M. Idéias de Modernidade e Sociologia no Brasil. Porto Alegre: UFRGS, 1999.

DRUCK, M.G. Terceirização: (des)fordizando a fábrica: um estudo do Complexo Petroquímico. São Paulo: Boitempo; Salvador: Edufba, 2001.

FERNANDES, F. A natureza sociológica da sociologia. São Paulo: Ática, 1980.

GONDIM, L.M.P.; LIMA, J.C. A pesquisa como artesanato intelectual: considerações sobre método e bom senso. 2. ed. São Carlos: Ufscar, 2006.

GUIMARÃES, N.; LEITE, M.P. A Sociologia do Trabalho industrial no Brasil: desafios e interpretações. Boletim Informativo e Bibliográfico de Ciências Sociais, Rio de Janeiro, n. 37, p. 39-59, 1994.

HESSEL, S. Indignez-vous. Paris: Indigène, 2010.

HIRATA, H. Nova divisão sexual do trabalho?: um olhar voltado para a empresa e a sociedade. São Paulo: Boitempo, 2002.

LEITE, M.P.; ARAÚJO, A.M.C. O trabalho reconfigurado: ensaios sobre o Brasil e México. São Paulo: Fapesp; Annablume, 2009.

LIMA, J.C. O trabalho e a utopia da igualdade social. Novos Estudos Cebrap, São Paulo, v. 89, p. 213-220, 2011.

LIMA, J.C. (Org.). Ligações perigosas: trabalho flexível e trabalho associado. São Paulo: Annablume, 2007.

LOPES, J.R.B. O ajustamento do trabalhador à indústria: mobilidade social e motivação. Revista Latinoamericana de Estudos do Trabalho, v. 16, n. 26, p. 221-260, 2011. 
MICELI, S. História das Ciências Sociais no Brasil. São Paulo: Vértice; Revista dos Tribunais; Idesp, 1989. v. 1.

MICELI, S. Intelectuais à brasileira. São Paulo: Cia das Letras, 2001.

MOREIRA, E.M.; OLIVEIRA, R.V. (Org.). O fenômeno da globalização em perspectiva local e multidimensional. João Pessoa: UFPB, 2009.

RODRIGUES, I.J. Sindicalismo e política: a trajetória da CUT (1983-1993). 2. ed. São Paulo: LTr, 2011.

RODRIGUES, I.J.; RAMALHO, J.R. (Org.). Trabalho e sindicato em antigos e novos territórios produtivos: comparações entre o $\mathrm{ABC}$ paulista e o sul fluminense. São Paulo: Annablume, 2007.

TANGUY, L. La Sociologie du Travail en France: enquête sur le travail des sociologues, 1950-1990. Paris: La Découverte, 2011.

TANGUY, L.; ROPÉ, F. Saberes e competências: o uso de tais noções na escola e na empresa. Campinas: Papirus, 1987.

TRIPIER, P. Historias de la Sociologia del Trabajo em Francia; nota crítica de Pierre Tripier (Resenha). Revista Latinoamericana de Estudos do Trabalho, v. 16, n. 26, p. 261279, 2011.

VILLAS BÔAS, G. A vocação das Ciências Sociais no Brasil: um estudo da sua produção em livros do acervo da Biblioteca Nacional - 1945 a 1966. Rio de Janeiro: Fundação Biblioteca Nacional, 2007.

Recebido em 19 de março de 2012.

Aprovado em 28 de março de 2012. 